Original Article

\title{
INTERVENTION OF CLINICAL PHARMACIST IN THE MANAGEMENT OF TYPE 2 DIABETES MELLITUS IN OUTPATIENTS
}

\author{
ANJU SARAH MATHEWS \\ Krupanidhi College of Pharmacy, Bengaluru, Karnataka, India \\ *Email: anjuz12@gmail.com \\ Received: 17 May 2021, Revised and Accepted: 18 Aug 2021
}

\begin{abstract}
Objective: The purpose of the study was to analyze the effect of clinical pharmacist intervention on glycemic control based on fasting blood glucose and glycosylated blood glucose level.

Methods: A randomized prospective interventional study was conducted in the outpatient department of a tertiary care hospital. Patients suffering from diabetes for a least 2 y were selected for the study based on the inclusion and exclusion criteria. The control group was not given any special pharmacist care, while the interventional group had a face-to-face interview, counseling, and telephonic follow-up during the study period. Based on the baseline values and endpoint parametric values, the result of the study was analyzed.
\end{abstract}

Results: The study was analyzed based on the difference in the glycemic index, using HbA1c and FBS values. The basal values of HbA1c were similar for both groups (8.5\%), but a marked reduction to $7.2 \%$ was observed in the interventional group. FBS values reduced from 208 mg/dl to 186 $\mathrm{mg} / \mathrm{dl}$ in the intervention group, while in the usual care group, the reduction was from $211 \mathrm{mg} / \mathrm{dl} \mathrm{to} 198 \mathrm{mg} / \mathrm{dl}$.

Conclusion: The inclusion of clinical pharmacists in the healthcare team can offer a remarkable improvement in patient's condition by providing more support in the therapy.

Keywords: Diabetes mellitus, Clinical pharmacist, Intervention, Glycosylated hemoglobin

(C) 2021 The Authors. Published by Innovare Academic Sciences Pvt Ltd. This is an open access article under the CC BY license (https://creativecommons.org/licenses/by/4.0/] DOI: https://dx.doi.org/10.22159/ijpps.2021v13i10.42435. Journal homepage: https://innovareacademics.in/journals/index.php/ijpps.

\section{INTRODUCTION}

Diabetes Mellitus is one of the worldwide fastest emerging chronic metabolic disease which results in significantly raised morbidity, mortality and healthcare expenses. The international Diabetes foundation estimates diabetes in one in ten adults and about $47 \%$ are under-diagnosed. Studies have shown that the risk factor for stroke and cardiovascular disease in diabetes patients is 2 to 3 times in contrast to patients having no hyperglycemia [1]. Moreover, the associated complications such as blindness, renal disease, and amputations increase health care costs dramatically high [2]. The cost of health care plans was calculated to be 2 to 3 times that of the patient of the same age without diabetes mellitus in the United States [3].

It was reported that there are different methods to prevent diabetes related morbidity [4]. One such method was by the utilization of the present management direction and positive changes in the monitoring of the pharmacotherapies, which included measuring blood sugar levels, and retinal screening. Patient education and motivation are the main two tools that can be applied to the clinical task for proper management of the condition. Most of the diabetes treatment purposes are mainly depending on self-management and life-altering changes of the patient. Therefore, the management of the complicated multisystem and patient-oriented problems in a healthcare system requires severe follow-ups and critical personalized patient counseling and proper medical education [5].

The number of diabetic patient's number is increasing yearly because of the increasing pervasiveness of both types of diabetes. To achieve strict control of diabetes, structured care is advised. In India, the diabetes clinical practice recommendations are inadequate in the primary care settings [6]. As a result, a number of modifications in the interventions designed to improve better metabolic control for diabetes patients have been developed [7]. Pharmacists are regarded as easy and fast accessible members of the healthcare team for the patients and are in a commendable status to participate in the professional care of the patients. Pharmacist-led, patient education and follow-up can improve the overall clinical outcome in patients.
The management of T2DM needs continuous medical care by the healthcare team and self-care by patients. Despite all new medications and specific care in modern hospitals, the control of diabetes remains still in question. Pharmacists-led healthcare concept is found to help diabetic patients achieve treatment goals and improve outcomes. So, the introduction of pharmaceutical care is found to improve adherence of the patients to the prescribed regimen and individualized care, which results in better control of diabetes have been reported [8].

\section{MATERIALS AND METHODS}

Patients in the age group 18 to $70 \mathrm{y}$ of age, belonging to either gender, diagnosed with Type- 2 diabetes mellitus for not more than 2 y were selected. Patients with severe renal and hepatic dysfunctions were excluded.

The study was conducted for a period of $12 \mathrm{mo}$, after gaining approval of the institutional Ethic committee (Approval no: JMCP/IEC-01A/PD-2018). During the period, patients who have diabetes for a maximum up to the past two years were selected. They were selected based on exclusion inclusion criteria and they were monitored. Patients who expressed willingness to participate in the study and otherwise satisfied the eligibility requirements were selected and the study details were well explained to all the participating patients and the duly signed informed consent was obtained. The selected patients were grouped randomly into interventional and usual care groups. The different intervention steps and the protocol of the study were explained to the patients included in the interventional group, whereas the normal care group was directed to follow their normal treatment protocol. Intervention procedures were applied to the selected interventional group, while the usual care group was not given any special attention or care in addition to normal care and information given by the healthcare team and pharmacist in the outpatient pharmacy department regarding the medications and therapeutic regimen.

The multifaceted interventions for the patients in the interventional group were comprised of two sessions, a face-to-face care by an 
interview and counseling followed by a telephonic follow up program. The interventional group was given regular six face-to-face informative sections spread over a period of 12 mo during their regular visit to the outpatient department for review. During this session the clinical pharmacist performed a $30 \mathrm{~min}$ face to face interaction and direct patient counseling.

The most important responsibilities of the pharmacist are the optimization of the therapy and to improve medication adherence. A systemic review has shown that the intervention of a pharmacist through face-to-face interactions, group activities and telephonic follow-up can improve adherence in medications for diabetes patients. The responsibility of clinical pharmacy and clinical pharmacist-led patient care is a novel concept in pharmaceutical care.

All the data collected were analyzed using SAS software. The demographic data and the baseline characteristics were summarized descriptively. Continuous variables were analyzed using unpaired $t$ test and categorical data was analyzed by using the chi-square test at the baseline as well as by the end of the study at $5 \%$ significance. All differences were tested at $\mathrm{p}=5$.

\section{RESULTS}

The fasting blood glucose levels were $208 \mathrm{mg} / \mathrm{dl}$ for the intervention group and $211 \mathrm{mg} / \mathrm{dl}$ and the usual care group at the baseline. The values were $198 \mathrm{mg} / \mathrm{dl}$ for the usual care and $186 \mathrm{mg} / \mathrm{dl}$ for the interventional group by the end of the study. In both groups the reduction was statistically significant. But the total reduction with the intervention group showed a statistical difference compared with the usual care group in group analysis (table 1, fig. 1).

At the baseline assessment, the HbA1c values (8.5\% and $8.7 \%)$ were similar for both interventional and usual care group. But, at the end of the study HbA1c values reduced to $7.2 \%$ and $8.5 \%$, respectively. The difference of the HbA1c percentage of the usual care group was not significant, but for the patients in the interventional group it was found significant. On compared with the usual care group, the interventional group patients achieved a greater reduction in the A1c values, which was clinically and statistically significant. It was found that in the intervention group the percentage of patients almost reached the American diabetes association goal $(\mathrm{HbA} 1 \mathrm{c} \leq 7 \%)$ was significantly higher compared to the usual care group.

Table 1: Outcomes in key biomedical values at baseline and end of study within and between groups

\begin{tabular}{|c|c|c|c|c|c|c|c|c|c|}
\hline \multirow{2}{*}{$\begin{array}{l}\text { Outcome } \\
\text { measures }\end{array}$} & \multicolumn{4}{|c|}{ Interventional group } & \multicolumn{4}{|c|}{ Usual care group } & \multirow{2}{*}{$\begin{array}{l}\text { Group } \\
\text { mean } \\
\text { difference }\end{array}$} \\
\hline & $\begin{array}{l}\text { Baseline } \\
\text { mean+SD } \\
\text { (median) }\end{array}$ & $\begin{array}{l}\text { End of study } \\
\text { mean+SD } \\
\text { (median) }\end{array}$ & $\begin{array}{l}\text { Mean } \\
\text { difference }\end{array}$ & $\begin{array}{l}\mathbf{p} \\
\text { value }\end{array}$ & $\begin{array}{l}\text { Baseline } \\
\text { mean+SD } \\
\text { (median) }\end{array}$ & $\begin{array}{l}\text { End of study } \\
\text { mean+SD } \\
\text { (median) }\end{array}$ & $\begin{array}{l}\text { Mean } \\
\text { difference }\end{array}$ & $\begin{array}{l}\mathbf{p} \\
\text { Value }\end{array}$ & \\
\hline $\begin{array}{l}\text { Fasting blood } \\
\text { sugar (mg/dl) }\end{array}$ & $\begin{array}{l}209.62 \pm 0.60 \\
(208.0)\end{array}$ & $\begin{array}{l}182.571 \pm 4.91 \\
(186.0)\end{array}$ & 27.06 & 0.00 & $\begin{array}{l}211.831 \pm 1.91 \\
(212.0)\end{array}$ & $\begin{array}{l}200.68 \pm 17.19 \\
(198.0)\end{array}$ & 11.144 & 0.001 & -15.912 \\
\hline $\operatorname{HbA1c}(\%)$ & $\begin{array}{l}8.56 \pm 0.69 \\
(8.5)\end{array}$ & $\begin{array}{l}7.360 \pm 0.76 \\
(7.2)\end{array}$ & 01.196 & 0.00 & $\begin{array}{l}8.710 \pm 0.74 \\
(8.7)\end{array}$ & $\begin{array}{l}8.570 \pm 0.95 \\
(8.5)\end{array}$ & 0.136 & 0.136 & -1.061 \\
\hline
\end{tabular}

HbA1c= Glycosylated haemoglobin

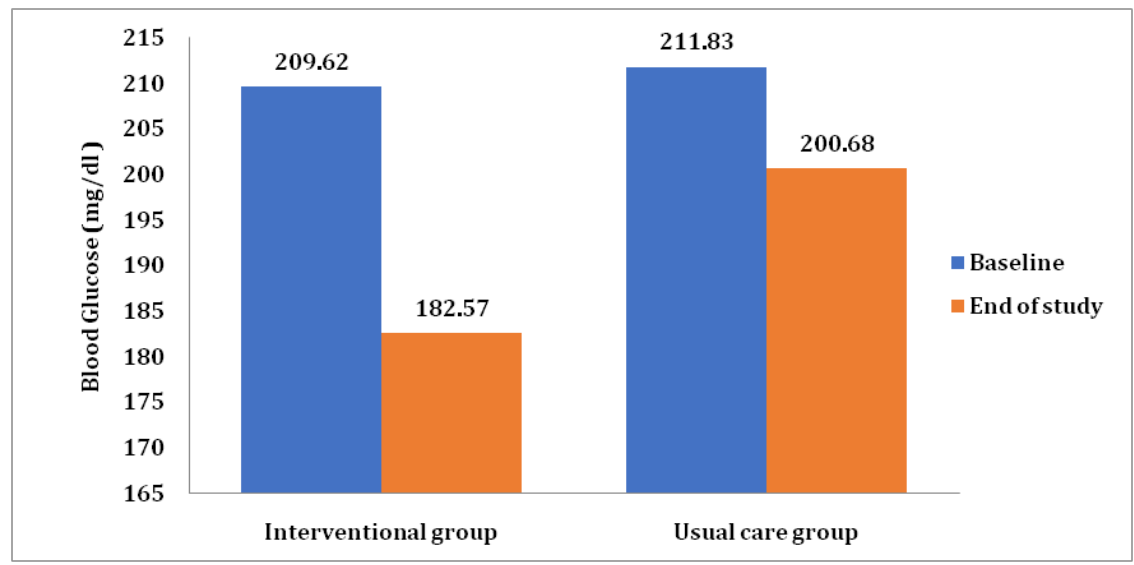

Fig. 1: Summary of fasting blood sugar

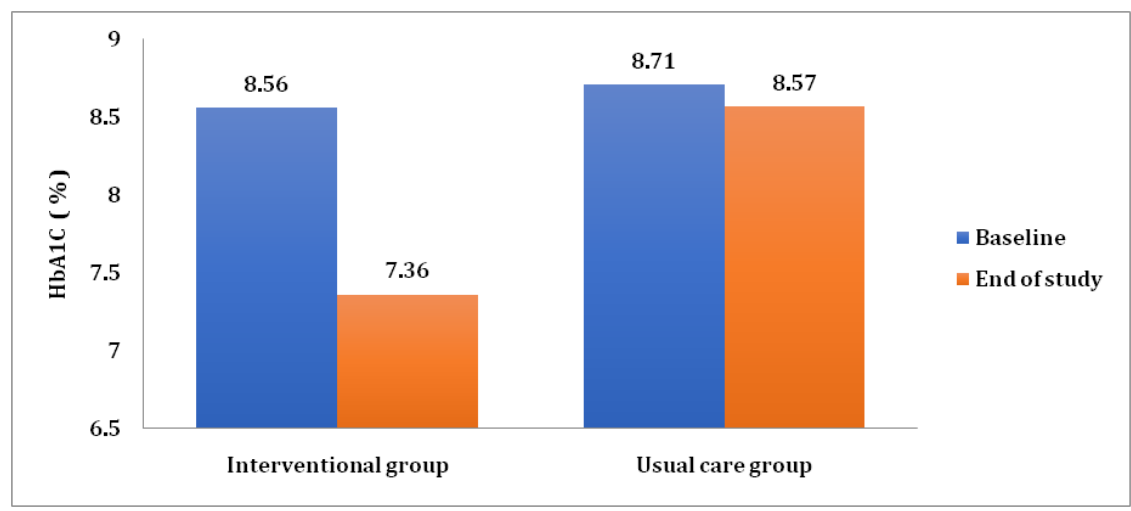

Fig. 2: Summary of glycosylated hemoglobin (HbA1c) 


\section{DISCUSSION}

Out of the 220 selected candidates, the study was completed by 106 patients in the interventional category and 104 patients in the usual care category. Among the four candidates from the intervention group discontinued, two were discontinued due to a change in their working area to other places in the government sector and two were changed to hospital for specialized treatment for their comorbidities. Among the six candidates in the usual care group, one changed hospital two candidates left the state to join their family and 3 went abroad with new job assignments.

In both the interventional group (61.3\%) and the usual care group $(57.7 \%)$ majority were females. The age group of the patients varied from 41 to 70 . Most of them belonged to the age group 56 to 60 indicated the complications of the chronic diseases and associated complications starts after $50 \mathrm{y}$ and before $60 \mathrm{y}$.

The most common existing chronic disease is diabetes globally [9]. It was measured by changes in the HbA1c and FBS. In our study, these were evaluated and found that significant reductions were brought by the intervention and monitoring of the glucose level at home. The diabetic outpatients were nowadays giving more attention to nonpharmacological lifestyle modifications for the management of blood glucose level.

The final goal of the therapy was to achieve the HbA1c level less than or equal to $7 \%$. It was achieved in the interventional group in $23.5 \%$ of the patients in the interventional group compared to $14.5 \%$ in the normally treated care group. Apart from the interactive involvement of the clinical pharmacist, there was diabetic education in the pharmacy for the diabetic patients, which also influenced patients belonging to both groups. Many studies conducted in diabetes patients showed improved glycemic control reported [10].

A significant reduction in HbA1c was observed in a study conducted among diabetes patients by the intervention pharmacist [11]. Another study reported that randomized controlled trials produced significant HbA1c levels within six months of duration due to the intervention of pharmacists [12].

Studies showed a significant statistical correlation between baseline glycemic values and final changes in HbA1c values. Most of the studies on diabetes showed a positive impact of pharmacist intervention. However, non-improvement adherence was also reported even after pharmacist intervention. Improvement in goal, was reported in pharmacist-managed diabetes patients [13].

A study conducted in Indonesia resulted in a decrease in mean HbAlc at all follow-ups and the number of patients with optimal HbAlc values increased after each follow-up [14]. Moreover, the lipid level improved at every measurement by about $50 \%$. Patients with higher baseline HbA1c values pharmacist controlled diabetes, high baseline expenses were shown to have revamped or reduce the costs respectively. Pharmacist-controlled diabetes care decreased medication costs which is a significant factor for Pharmacoeconomics [15].

The need for clinical pharmacy services focused on diabetes, specifically in ambulatory care centre has been increased due to the increased mortality and morbidity due to diabetes. A retrospective study in which they evaluated outcomes for the management of diabetes referred to a clinical pharmacist with a control group who are not seen by a clinical pharmacist. It was observed that the diabetic patients who were managed by the clinical pharmacist had a higher decrease in HbAlc compared with the control group and also a reduction in the emergency department visits [16].

A study it was found that the basic outcome assessments in the changes in HbA1c, blood sugar were significantly decreased because of pharmacist participation in direct care. It was reported that the $\mathrm{HbA1c}$ was changed from the baseline by $2.2 \%$, fasting blood sugar minimized by $65 \mathrm{mg} / \mathrm{dl}$ and the random blood sugar reduced by about $80 \mathrm{mg} / \mathrm{dl}$.

These results are similar to reviews performed by Yaghoubi et al., who have demonstrated a clinically significant decrease in HbA1c levels leading to improvement in type 2 diabetes condition [17]. It was also demonstrated a beneficial effect of pharmacist-led interventions when compared with normal care patients.
Interventions with the active participation of pharmacist-centered diabetes awareness were comparable influence to pharmacist-led teaching and pharmacy care for blood sugar control measured as HbA1c and FBS along with several secondary clinical outcomes of the clinical responses. Health professionals are also supposed to provide a piece of proper knowledge to the patients regarding the role of pharmacotherapy and diet in diabetes control and its effect on these outcomes [18].

Our study demonstrated a $0.95 \%$ to $1.19 \%$ mean reduction in HbA1c compared with usual care within the first six months. Other studies which were conducted as pharmacist-based programs in other multidisciplinary health care settings were also shown a similar decrease in HbA1c from baseline with proactive pharmacist management [19]. However, some of these studies had fewer patients and shorter follow-up time periods. In a study, it was reported that diabetes patients managed by a pharmacist in a diabetes service center started with a mean HbA1c of $9 \%$ and has decreased to $7.5 \%$ after seven months of follow-up, which was statistically significant over the control group.

All these studies justified our finding of decreased blood sugar levels manifested by the reduction in the fasting blood sugar and HbA1c by interventions of the clinical pharmacist with patient counseling, diabetic education and personal follow up ultimately resulting in improved glycemic control.

\section{CONCLUSION}

The clinical pharmacist intervention resulted in a significant improvement in HbA1c and fasting blood glucose. During the study, the clinical pharmacist was involved in patient counselling and patient education to optimize pharmacotherapy. It was achieved through personal face-to-face interactions, supply of literatures and telephonic follow up. This has created an awareness of the patient not only in the appropriate use of medication but also the lifestyle modifications. The study also made an impact on the usual care group with their personal contacts with the intervention group members. Therefore, improved clinical outcomes were also observed in the usual care group.

\section{GLYCEMIC CONTROL}

In this study, the HbA1c value did not change much in the usual care group, whereas it was significantly reduced in the interventional category of patients.

The Fasting Blood Sugar (FBS) level decreased in both usual care groups due to the improved diabetes care in the outpatient departments. But more pharmaceutical care do show a significant improvement in the other.

The preeminent finding related to the blood glucose monitoring was that 37 percentage of the interventional group achieved the American Diabetes Association (ADA) target in the 12 mo of followup. It is further proved that pharmaceutical care can result in a significant effect in blood glucose management in multiple clinical morbid conditions.

\section{LIMITATION}

One of the most important limitations was that in the retrospective observational study the patient data was collected from a single hospital, comparatively small patient size and a short follow-up study period. Interventions were carried out by a single clinical pharmacist.

The study participants were treated by the same physician and by the same clinical pharmacist, so some of the positive clinical outcomes may be extrapolated to the normal group resulting improved outcomes in the group.

\section{FUNDING}

Nil

\section{AUTHOR CONTRIBUTION}

The author has actively participated in the research work and in writing the manuscript. 


\section{CONFLICT OF INTERESTS}

Declared none

\section{REFERENCES}

1. Lindenmeyer A, Hearnshaw H, Vermeire E, Van Royen P, Wens $\mathrm{J}$, Biot Y. Interventions to improve adherence to medication in people with type 2 diabetes mellitus: a review of the literature on the role of pharmacists. J Clin Pharm Ther. 2006;31(5):40919. doi: 10.1111/j.1365-2710.2006.00759.x, PMID 16958818.

2. Adler AI, Stratton IM, Neil HA, Yudkin JS, Matthews DR, Cull CA, Wright AD, Turner RC, Holman RR. Association of systolic blood pressure with macrovascular and microvascular complications of type 2 Diabetes (UKPDS 36): prospective observational study. BMJ. 2000;321(7258):412-9. doi: 10.1136/bmj.321.7258.412, PMID 10938049.

3. Blalock Susan J, Roberts Andrew W, Lauffenburger Julie C, Thompson Trey, O'Connor Shanna K. The effect of community pharmacy-based interventions on patient health outcomes: a systematic review. Med Care Res Rev. 2013;70(3):235-66. doi: $10.1177 / 1077558712459215$, PMID 23035056.

4. Chrvala Carole A, Sherr Dawn, Lipman Ruth D. Diabetes selfmanagement education for adults with type 2 diabetes mellitus: a systematic review of the effect on glycemic control. Patient Educ Couns. 2016;99(6):926-43. doi: 10.1016/ j.pec.2015.11.003, PMID 26658704.

5. Benedict Amanda, W Spence, Michele M, Sie John L, Chin Helen A, Ngo Chi D, Salmingo Jennifer F, Vidaurreta Andrew T, Rashid Nazia. Evaluation of a pharmacist-managed diabetes program in a primary care setting within an integrated health care system. J Manag Care Spec Pharm. 2018 Feb;24(2):114-22. doi: 10.18553/jmcp.2018.24.2.114, PMID 29384029.

6. Choe Hae Mi, Mitrovich Sonya, Dubay Daniel, Hayward Rodney A, Krein Sarah L, Vijan Sandeep. Proactive case management of high-risk patients with type 2 diabetes mellitus by a clinical pharmacist: A randomized controlled trial. Am J Manag Care. 2005;11(4):253-60. PMID 15839185.

7. Renders CM, Valk GD, Griffin SJ, Wagner EH, Eijk Van JT, Assendelft WJ. Interventions to improve the management of diabetes in primary care, outpatient, and community settings: a systematic review. Diabetes Care. 2001;24(10):1821-33. doi: 10.2337/diacare.24.10.1821. PMID 11574449.

8. Korcegez Eylem Ilktac, Sancar Mesut, Demirkan Kutay. Effect of a pharmacist-led program on improving outcomes in patients with type 2 diabetes mellitus from northern cyprus: a randomized controlled trial. J Manag Care Spec Pharm. 2017;23(5):573-82. doi: 10.18553/jmcp.2017.23.5.573, PMID 28448779.

9. Bukhsh Allah, Khan Tahir M, Lee Shaun WH, Lee Learn-Han, Chan Kok-Gan, Goh Bey-Hing. Efficacy of pharmacist-based diabetes educational interventions on clinical outcomes of adults with type 2 diabetes mellitus: a network meta-analysis. Front Pharmacol. 2018;9:339. doi: 10.3389/fphar.2018.00339, PMID 29692730.

10. Jarab Anan Sadeq, Alqudah Salam Ghazi, Mukattash Tareq Lewis, Shattat Ghassan, Al-Qirim Tariq. Randomized controlled trial of clinical pharmacy management of patients with type 2 diabetes in an outpatient diabetes clinic in Jordan. J Manag Care Pharm. 2012;18(7):516-26. doi: 10.18553/jmcp.2012.18.7.516. PMID 22971205.

11. Presley Bobby, Groot Wim, Pavlova Milena. Pharmacy-led interventions to improve medication adherence among adults with diabetes: a systematic review and meta-analysis. Res Social Adm Pharm. 2019;15(9):1057-67. doi: 10.1016/j.sapharm.2018.09.021. PMID 30685443.

12. Mathew Arun, Palur Venkat, Venkateswaramurthy. A study of impact of clinical pharmacist intervention on the relationship between treatment satisfaction and medication adherence in hypertensive patients. J Pharm Sci Res. 2016;8:190-7.

13. Funnell Martha M, Brown Tammy L, Childs Belinda P, Haas Linda B, Hosey Gwen M, Jensen Brian, Maryniuk Melinda, Peyrot Mark, Piette John D, Reader Diane, Siminerio Linda M, Weinger Katie, Weiss Michael A. National standards for diabetes self-management education. Diabetes Care. 2009;32;Suppl 1:S87-94. doi: 10.2337/dc09-S087, PMID 19118294.

14. Sauriasari Rani, Sakti Ridho Muhammad. Impact of a pharmacist-led patient education initiative on glycemic control of patients with type 2 diabetes mellitus: a single-center experience in West Jakarta, Indonesia. Int J App Pharm. 2018;10(1):252-6. doi: 10.22159/ijap.2018.v10s1.56.

15. Yaghoubi Mohsen, Mansell Kerry, Vatanparastc Hassanali, Steeves Megan, Zeng, Farag Marwa. Effects of pharmacy-based interventions on the control and management of diabetes in adults: a systematic review and meta-analysis. Can J Diabetes. 2017;41(6):628-41. doi: 10.1016/j.jcjd.2017.09.014, PMID 29224636.

16. Syed Wajid Menaka M, Ahmed Fazil, Samreen Sana. A literature review on oral hypoglycemic agents-mechanistic aspects. Asian J Pharm Clin Res. 2019;12:5-10.

17. Butt Mubashra, Mhd Ali Adliah, Bakry Mohd Makmor, Mustafa Norlaila. Impact of a pharmacist-led diabetes mellitus intervention on $\mathrm{HbA1c}$, medication adherence and quality of life: a randomised controlled study. Saudi Pharm J. 2016;24(1):40-8. doi: 10.1016/j.jsps.2015.02.023. PMID 26903767.

18. Toklu Hale Zerrin, Hussain Azhar. The changing face of pharmacy practice and the need for a new model of pharmacy education. J Young Pharm. 2013;5(2):38-40. doi: 10.1016/j.jyp.2012.09.001, PMID 24023452.

19. Chung Nancy, Rascati Karen, Lopez Debra, Jokerst Jason, Garza Aida. Impact of a clinical pharmacy program on changes in hemoglobin A1c, diabetes-related hospitalizations, and diabetes-related emergency department visits for patients with diabetes in an underserved population. J Manag Care Spec Pharm. 2014;20(9):914-9. doi: 10.18553/jmcp.2014.20.9.914, PMID 25166290.

20. Holsclaw Susan L, Olson Kari L, Hornak Roseanne, Denham Anne M. Assessment of patient satisfaction with telephone and mail interventions provided by a clinical pharmacy cardiac risk reduction service. J Manag Care Pharm. 2005;11(5):403-9. doi: 10.18553/jmcp.2005.11.5.403. PMID 15934799. 